Letters for publication in the Correspondence columns should be addressed to:

The Editor, British Journal of Psychiatry, 17 Belgrave Square, London SWIX 8PG

\section{NEW LONG-STAY PATIENTS IN A HOSPITAL FOR MENTAL HANDICAP \\ DeAr Sir,}

Dr Spencer has reported (Journal, January 1977, 130, $p$ 104) that a proportion of clients transferred to Meanwood Park Hospital remained there for a long time.

He asserts that the only or most appropriate intervention that could have been performed for these clients was to transfer them to Meanwood Park Hospital. However, he cannot be said to have justified this assertion, because he has not provided any description of what each client in Meanwood Park Hospital does throughout each day or any description of the unique components of Meanwood Park Hospital necessary to attain this level and range of activity.

He further asserts that only those facilities that are labelled similarly to Meanwood Park (i.e. 'Hospital'), and staffed by persons labelled similarly to the staff of Meanwood Park (i.e. 'nurse', 'doctor', 'auxiliary', etc) are appropriate places of residence for any other similar clients. Again, he has presented no evidence to support this assertion.

He gives no information for any client, on current problems, targets, interventions implemented or progress made, but suggests, wrongly, that the only conceivable target for clients in hospital is transfer out of hospital.

It is obvious that many possible service options differing markedly from Meanwood Park Hospital could achieve the minimal criteria described by Dr Spencer-namely, the maintenance of clients without specification of problems, targets and interventions or the documentation of progress. We believe, however, that it is important to investigate what arrangements of resources (service options) can be shown to achieve the criteria we proposed in this Journal (September 1976, 129, pp 287-8).

There may be many alternative service options, but they can only be tested, and a rational choice made between them, if service personnel document precisely what they are doing (interventions), to what end (targets) and why (problems). Both they and other observers will then be able to judge whether or not services are attaining 'progressive and enlightened aims', and also what skills and performances are required if they are to do so.

The new and exciting advances being made in this field necessitate, as a priority, the setting of precise performance standards. We have made the case for this in detail in our evidence to the Jay Committee (Kushlich et al, 1976).

\section{Albert Kushlick \\ David Felce \\ John PALMer JOHN SMTTH}

Health Care Evaluation Research Team,

Dawen House, Sleepers Hill, Winchester SO22 $4 \mathrm{NG}$

\section{Reference}

Kushlich, A., Felce, D., Palmer, J. \& Smith, J. (1976) Evidence to the Committee of Inquiry into Mental Handicap Nursing and Care from the Health Care Evaluation Research Team, Winchester. Duplicated.

\section{DO ALCOHOLICS NEED VITAMINS?}

DeAr Sir,

There have been numerous investigations $(1,2,3)$ into the folate and $\mathrm{B}^{12}$ status of patients with the diagnosis of alcoholism. Serum folate is generally held to be a good index of dietary deficiency. The body stores of folate are small, and severe dietary deficiency usually manifests itself within about six weeks in low serum levels. Because of this, most physicians will treat alcoholics with high doses of vitamins with the idea of replenishing the patient's nutritional status as soon as possible (4).

I should like to report the folate and $\mathrm{B}^{\mathrm{I} 2}$ status of 66 alcoholic patients admitted to a Regional Alcoholic Unit (Bexley Hospital, Old Bexley, Kent). Serum was collected, usually on the first day of admission, before routine vitamins supplements were administered. Serum folate concentration and vitamin $B^{12}$ concentration were assayed microbiologically, using Lactobacillus casei and Lactobacillus leichmanni, respectively (5).

Different opinions exist regarding the normal folate levels in the general population. In this communication I follow the classification used by Reynolds and 